\title{
Investigation of coeliac trunk and superior mesenteric artery variations and literature review
}

\author{
Hadi Sasani ${ }^{1}$, Nergiz Ekmen ${ }^{2}$ \\ ${ }^{1}$ Department of Radiology, Faculty of Medicine, Tekirdag Namık Kemal University,Tekirdag, Turkey \\ ${ }^{2}$ Department of Gastroenterology, Faculty of Medicine, Gazi University, Ankara, Turkey
}

Received: 2021-04-08.

Accepted: 2021-07-10

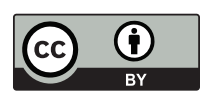

This work is licensed under a Creative Commons Attribution 4.0 International License

J Clin Med Kaz 2021; 18(4):81-86

Corresponding author:

Hadi Sasani.

Email: hsasani@nku.edu.tr;

ORCID: 0000-0001-6236-4123

\section{Abstract}

Aim: To evaluate the variations of coeliac trunk (CTR) and superior mesenteric artery (SMA) variations in Tekirdag province using computed tomography (CT) images.

Material and methods: The data of the patients who underwent CT angiography for any reason via the hospital online PACS were scanned retrospectively for CTR and SMA variation. The frequency of variation in the study population, the variation type and distribution by gender were statistically analyzed.

Results: A total of 2529 individuals, including 1703 (67.3\%) males and 826 (32.7\%) females, were included in the study. The prevalence of variation in the study group was $25.7 \%(n=650)$, and it was seen that there was a single variation in 579 (89.1\%) individuals and a double variation in 71 (10.9\%) individuals. The three most common variations were replaced right hepatic artery (HA) from SMA origin, LGA originated replaced left $\mathrm{HA}$, and common HA from SMA origin ( $n=340,13.44 \% ; n=120,4.74 \%$ and $\mathrm{n}=46,1.82 \%$, respectively).

Conclusion: Information the rates of these vascular variations provide contribution to surgical procedures and prevents more serious complications. Also, it should be carefully investigated in terms of other accompanying variation. variation

Key words: celiac artery, mesentery, computed tomography,

\section{Introduction}

The aorta abdominalis (AA) is the continuation of the descending aorta after passing the midline diaphragm through the hiatus aorticus at the lower edge of T12 vertebra. AA gives branches from the ventral, lateral and dorsal aspects. Ventral branches are single and provide blood supply to the abdominal viscera $[1,2]$.

During embryonic period, from the 10th to 13th vitelline arteries that communicate between the aorta and a primitive ventral anastomotic artery. The regression of the ventral anastomosis and vitelline arteries (11th and 12th) and the persistent of the 10th and 13th roots provide giving origin to the coeliac trunk (CTR) and superior mesenteric artery (SMA). These branches emerge in a single form, extending towards the primitive digestive tract after the fusion of aortae dorsales during embryogenesis. While the right gastric artery, left gastric artery (LGA) and hepatic arteries (HA) are formed from the ventral splanchnic anastomosis, the dorsal splanchnic anastomosis forms the first branches of the gastrosplenic artery, pancreaticodudenal artery and colic artery [1-3].
CTR is the first of the ventral branches and is separated from the aorta abdominalis $20-30 \mathrm{~mm}$ below the aortic hiatus. This artery has three main branches separated from the same point including splenic artery (SA), common hepatic artery (CHA), and LGA (Figure 1). In a less common type, LGA is split first, then SA and CHA are split into a separate root $[2,4,5]$.

SMA, just below the CTR, separating from the abdominal aorta at the level of L1 vertebral body, running down in front of the third part of the duodenum and supplies small intestine [4-8].

Imaging plays an important role in the detection of arterial variations. For this purpose digital subtraction angiography (DSA) and cross sectional imaging modalities including computed tomography angiography (CTA) or magnetic resonance angiography (MRA) can be used. However, due to its minimal-invasive nature and recent advances in multidetector CT technology, thin-slice dynamic CT has replaced DSA for vascular assessment [9]. 


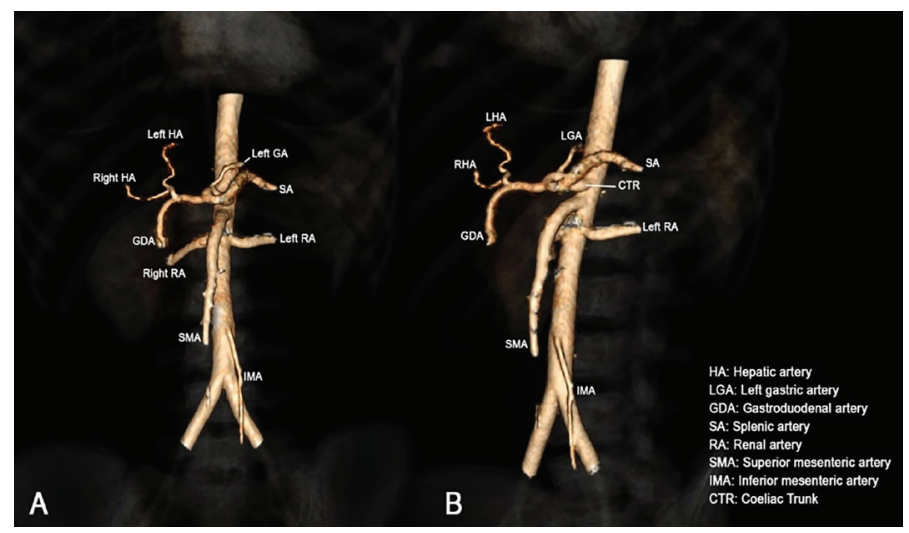

Figure 1 - Three-dimensional reformat CTA images $(A, B)$ show a normal arterial anatomy (HA: Hepatic artery, LGA: Left gastric artery, GDA: Gastroduodenal artery, SA: Splenic artery, RA: Renal artery, SMA: superior mesenteric artery, IMA: inferior mesenteric artery, CTR: Coeliac trunk).

The common occurrence of embryologically based variations in the anatomy of the ventral branches of the abdominal aorta requires a detailed knowledge at imaging. Therefore, the preoperative knowledge of CTR variations or before the interventional procedure, is important for physicians in order to reduce the risk of complications in abdominal dissection, radiological interventions (such as celiac and chemoembolization of liver tumors) or surgical procedures (such as liver transplantation, laparoscopic surgery, radical gastrectomy) [10-12].

In our study, we aimed to examine the variations of major arteries that play a role in nutrition of digestive organs such as stomach, liver and pancreas.

\section{Material and methods Patient collection}

Between March 01, 2017 and June 15, 2021, patients with any indications who had contrast-enhanced CT angiographic examinations showing CTR structures were scanned from the archiving and communication system (PACS) in the radiology department of Tekirdağ Namık Kemal University Medical Faculty Hospital. The frequency of variation in the study population, the variation type and distribution by gender were statistically analyzed.

\section{Inclusion and exclusion criteria}

Examinations including abdominal vascular structures (coeliac trunk, superior mesentery artery and/or renal arteries) and CT angiography images with best quality of diagnostic imaging were enrolled in the study.

CT examinations with poor image quality, non-enhanced CT images and those including pathologies affecting vascular structures (any intervention / surgery, stenosis, aneurysm, tumor) were excluded from the study.

\section{Ethical approval}

This study was approved by the university / local human research ethics committee and all procedures performed in studies involving human participants were in accordance with the ethical standards of the institutional and/or national research committee and with the 1964 Helsinki Declaration and its later amendments or comparable ethical standards (Approval Number: 2019.193.10.14)

\section{Data Acquisition}

CT acquisitions were performed on 128 row multi-detector CT device (MDCT; Aquilion Prime, Toshiba, Otawara, Japan).

\section{Scanning protocol}

CT scanning parameters were as following for each protocol: 100-250 mAs modulated by personal body mass index dose; $100-140 \mathrm{kV}$ tube voltage, $0.5 \mathrm{~mm}$ x 80 collimation, 0.35 second gantry rotation time, 0.813 pitch factor, slice thickness 1 $\mathrm{mm}$, slice interval $0.8 \mathrm{~mm}$ and $5 \times 5 \mathrm{~mm}$ reconstruction interval. For intravenous bolus injection of non-ionic contrast material (350 mg/100 ml, iohexol, Omnipaque; GE Healthcare, Cork, Ireland) a mechanical injector was used at a flow rate of 4.5-5.0 $\mathrm{ml} / \mathrm{sec}$.

\section{Statistical analysis}

Statistical analyzes were carried out using a statistical package program (SPSS version 17, Chicago, USA). In order to determine the prevalence in the population, the cases with variations detected in the study were compared to the general population. Their correlation with other accompanying artery variations were examined using Pearson chi-square test in the evaluation of categorical data. Statistical significance level was accepted as $\mathrm{p}<0.05$.

\section{Results \\ Study population}

CT data of a total of 4972 patients were scrutinized from PACS retrospectively. From this population 2529 individuals, $1703(67.3 \%)$ male and $826(32.7 \%)$ female, were included in the study. There was a single or double variation (co-variation) in $25.7 \%(n=650)$ of these patients (Figure 2$)$. In the variation group, $68 \%(n=442)$ of the patients were male, and there was no statistically significant difference between the groups in terms of variation and gender $(\mathrm{p}=0.677)$. The mean age of the patients was $59.4 \pm 15.92$ years (minimum 8 years, maximum 103 years).

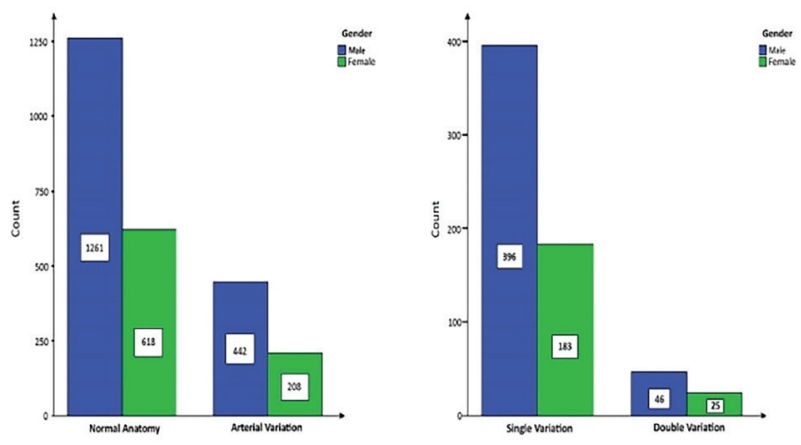

Figure 2 - (A) Diagram shows the distribution of normal anatomy and arterial variation by gender, (B) The distribution of number of variations by gender.

While single variation was found in $579(89.1 \%)$ of 650 patients with variation, double variation was detected in 71 (10.9\%) including $46(64.8 \%)$ males and 25 (35.2\%) females. There was no statistically significant difference in terms of gender between the groups with single and double variation $(\mathrm{p}=0.539)$.

The variations by gender are summarized in Table 1 . While the most common variation was found to be replaced right HA from SMA origin in 340 individuals $(65.9 \%, n=234$ in males) (Figure 3), the second most common variation in 120 people was LGA originated replaced left HA (65\%, n=78 males) (Figure 4) 


\begin{tabular}{|c|c|c|c|c|c|c|c|}
\hline \multirow{2}{*}{\multicolumn{2}{|c|}{ Variation type }} & \multirow{2}{*}{\multicolumn{2}{|c|}{ Male }} & \multirow{2}{*}{\multicolumn{2}{|c|}{ Female }} & \multirow{2}{*}{\multicolumn{2}{|c|}{ Prevelance* }} \\
\hline & & & & & & & \\
\hline 1) & Replaced right HA from SMA origin & \begin{tabular}{|l|}
$\mathrm{n}$ \\
224 \\
\end{tabular} & \begin{tabular}{|l|}
$\%$ \\
65.9 \\
\end{tabular} & \begin{tabular}{|l}
$\mathrm{n}$ \\
116 \\
\end{tabular} & \begin{tabular}{|l|}
$\%$ \\
34.1 \\
\end{tabular} & \begin{tabular}{|l|}
$\mathrm{n}$ \\
340 \\
\end{tabular} & \begin{tabular}{|l|}
$\%$ \\
13.44 \\
\end{tabular} \\
\hline 2) & Replaced left HA from LGA & 78 & 65.0 & 42 & 35.0 & 120 & 4.74 \\
\hline 3) & Common HA from SMA origin & 31 & 67.4 & 15 & 32.6 & 46 & 1.82 \\
\hline 4) & Coeliacomesenteric trunk & 23 & 79.3 & 6 & 20.7 & 29 & 1.15 \\
\hline 5) & Right $\mathrm{HA}$ from common HA & 16 & 72.7 & 6 & 27.3 & 22 & 0.87 \\
\hline 6) & Left HA from CHA & 10 & 66.7 & 5 & 33.3 & 15 & 0.59 \\
\hline 7) & Replaced right HA from coeliac trunk & 11 & 84.6 & 2 & 15.4 & 13 & 0.51 \\
\hline 8) & Accessory right HA from SMA origin & 9 & 81.8 & 2 & 18.2 & 11 & 0.43 \\
\hline 9) & CHA and SA from aortic origin & 6 & 66.7 & 3 & 33.3 & 9 & 0.36 \\
\hline 10) & 4A segment arterial branch from proper hepatic artery origin & 5 & 71.4 & 2 & 28.6 & 7 & 0.28 \\
\hline 11) & Replaced right HA from aortic origin & 4 & 80.0 & 1 & 20.0 & 5 & 0.20 \\
\hline 12) & Absent trunk & 4 & 100.0 & 0 & 00.0 & 4 & 0.16 \\
\hline 13) & Accessory right HA from proper HA origin & 2 & 66.7 & 1 & 33.3 & 3 & 0.12 \\
\hline 14) & LGA from aortic origin & 2 & 66.7 & 1 & 33.3 & 3 & 0.12 \\
\hline 15) & 4A segment arterial branch and left HA from proper HA origin & 2 & 100.0 & 0 & 00.0 & 2 & 0.08 \\
\hline 16) & LGA from SA origin & 0 & 00.0 & 2 & 100.0 & 2 & 0.08 \\
\hline 17) & SA from aortic origin & 1 & 50.0 & 1 & 50.0 & 2 & 0.08 \\
\hline 18) & Accessory left HA from LGA origin & 2 & 100.0 & 0 & 00.0 & 2 & 0.08 \\
\hline 19) & Accessory right $\mathrm{HA}$ from GDA origin & 1 & 100.0 & 0 & 00.0 & 1 & 0.04 \\
\hline 20) & Right HA and LGA from CHA origin & 1 & 100.0 & 0 & 00.0 & 1 & 0.04 \\
\hline 21) & Right and left HA(s) from CTR origin & 1 & 100.0 & 0 & 00.0 & 1 & 0.04 \\
\hline 22) & Accessory LGA from proper HA origin & 1 & 100.0 & 0 & 00.0 & 1 & 0.04 \\
\hline 23) & Left HA from coeliac CTR origin & 0 & 00.0 & 1 & 100.0 & 1 & 0.04 \\
\hline 24) & CHA, SA, LGA and left HA from aortic origin & 1 & 100.0 & 0 & 00.0 & 1 & 0.04 \\
\hline 25) & GDA from SA origin & 1 & 100.0 & 0 & 00.0 & 1 & 0.04 \\
\hline 26) & 4A segment arterial branch and left HA from CHA origin & 0 & 00.0 & 1 & 100.0 & 1 & 0.04 \\
\hline 27) & CHA and LGA from SMA origin & 1 & 100.0 & 0 & 00.0 & 1 & 0.04 \\
\hline 28) & SA from SMA origin & 1 & 100.0 & 0 & 00.0 & 1 & 0.04 \\
\hline 29) & LGA and left HA originated from CTR & 1 & 100.0 & 0 & 00.0 & 1 & 0.04 \\
\hline 30) & LGA and left HA originating from a common trunk & 1 & 100.0 & 0 & 00.0 & 1 & 0.04 \\
\hline 31) & 4A segment arterial branch from CHA origin & 1 & 100.0 & 0 & 00.0 & 1 & 0.04 \\
\hline 32) & Proper HA from aortic origin & 1 & 100.0 & 0 & 00.0 & 1 & 0.04 \\
\hline 33) & LGA origin accessory left HA & 1 & 100.0 & 0 & 00.0 & 1 & 0.04 \\
\hline
\end{tabular}

HA: Hepatic artery, LGA: Left gastric artery, GDA: Gastroduodenal artery, SA: Splenic artery, SMA: superior mesenteric artery, CTR: Coeliac trunk. * Refers to the frequency in the study group.

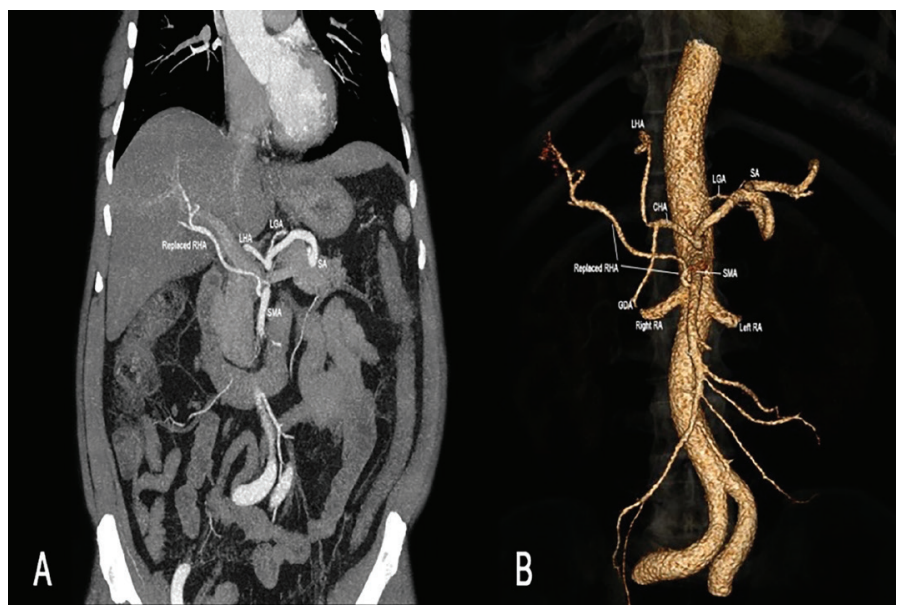

Figure 3 - Coronal CTA (A) and 3D-reconstruction (B) images show a replaced right HA from SMA origin.

and the third common variation was Common HA from SMA origin in 46 individuals $(67.4 \%, \mathrm{n}=31$, most commonly in males) (Figure 5).

In the current study, co-variation (double variation) was found in $10.9 \%(n=71)$ of the cases (Figure 2B, Table 2).

Journal of Clinical Medicine of Kazakhstan: 2021 Volume 18, Issue 4

\section{CT data}

Scanning regions in CT were categorized into four groups including thoracic (175), thoracic-abdominal (649), abdominal (494) and abdomino-peripheral (1211).

\section{Discussion}

CTR can show a wide variety of variations. It has become very important and necessary to know these variations in order to perform surgical and interventional radiological procedures more safely. Considering the growing number of living donor liver and kidney transplants in recent years, the importance of this issue has become clearer. Technical developments in abdominal surgery have increased the importance of preoperative radiological examinations, and the early detection of these variations has directly affected the success of surgical and interventional radiological procedures [13-15].

In this study, while normal vascular anatomy rate was $74.3 \%$, it was reported as $63.6 \%$ by Fargani et al [16], $89 \%$ by Michel NA [17], $51 \%$ by Winston et al [18], 66\% by De Cecco [19], and $89 \%$ by Song et al [9].

In the study conducted by Farghadani et al., the frequency of variation detected by CT angiography was $36.1 \%$, and the 


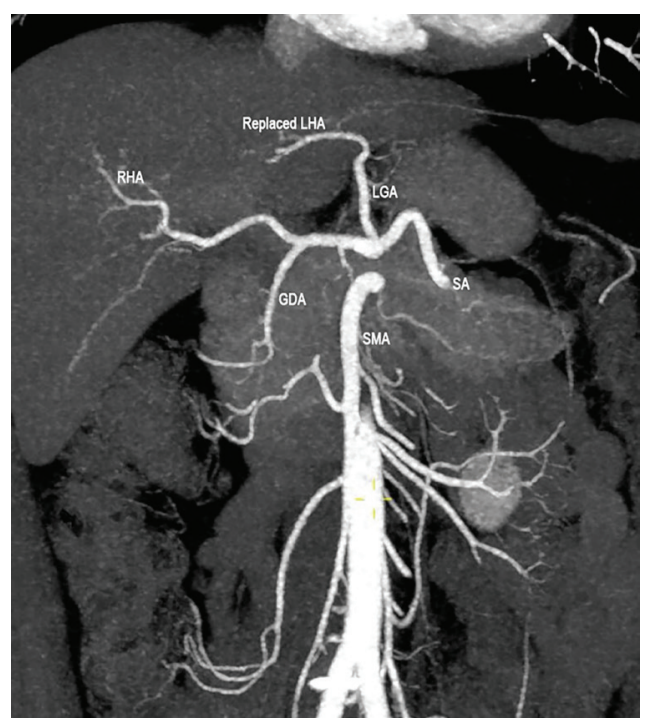

Figure 4 - Coronal CTA image shows a replaced left HA from LCA origin.

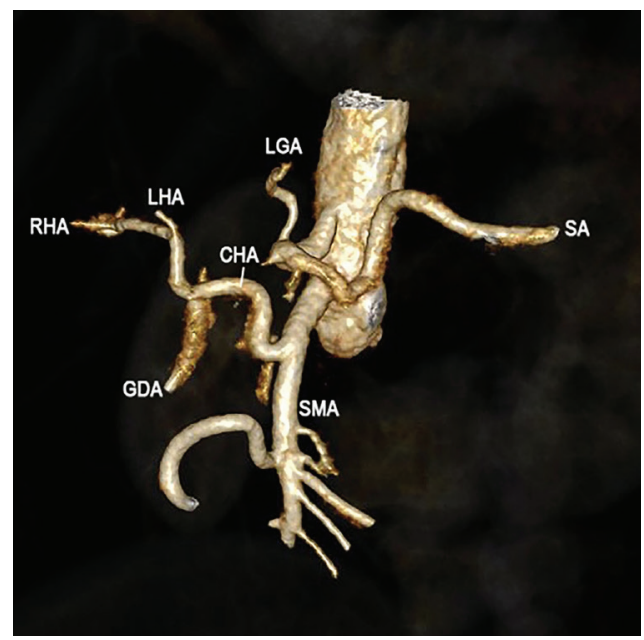

Figure 6 - Three-dimensional reconstruction CTA image shows a variation of $\mathrm{CHA}$ from SMA origin.

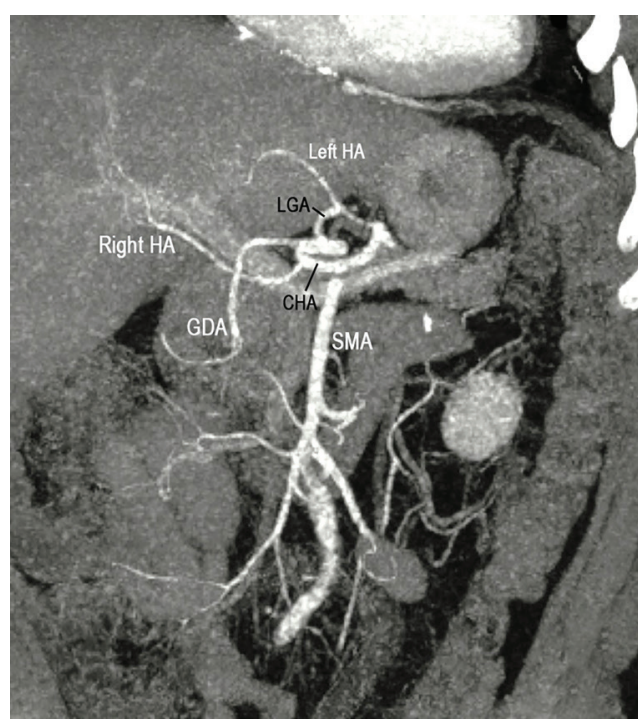

Figure 5 - Coronal plan CTA image shows a replaced left HA from LGA origin and right HA originating from $\mathrm{CHA}$.

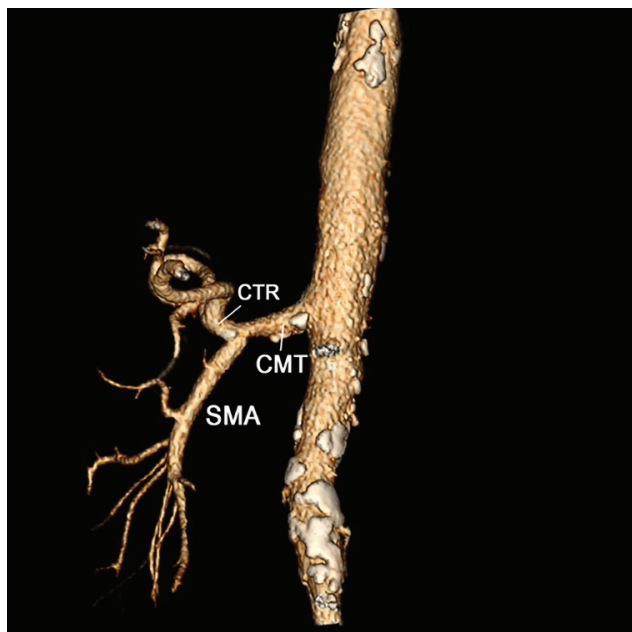

Figure 7 - Three-dimensional reconstruction CTA image shows a coeliacomesenteric trunk (CMT) variation.

\begin{tabular}{|c|c|c|c|c|c|c|c|}
\hline \multicolumn{2}{|r|}{ Variation type } & \multicolumn{2}{|c|}{ Male } & \multicolumn{2}{|c|}{ Female } & \multicolumn{2}{|c|}{ Prevelance* } \\
\hline & & $\mathrm{n}$ & $\%$ & $\mathrm{n}$ & $\%$ & $\mathrm{n}$ & $\%$ \\
\hline 1) & Replaced left HA from LGA & 36 & 69.2 & 16 & 30.8 & 52 & 2.1 \\
\hline 2) & LGA from aortic origin & 3 & 60.0 & 2 & 40.0 & 5 & 0.2 \\
\hline 3) & CHA and SA from aortic origin & 1 & 25.0 & 3 & 75.0 & 4 & 0.2 \\
\hline 4) & Replaced right HA from SMA origin & 1 & 100.0 & 0 & 0 & 1 & 0.0 \\
\hline 5) & Left HA from CHA origin & 1 & 100.0 & 0 & 0 & 1 & 0.0 \\
\hline 6) & CHA, SA and GDA from aortic origin & 1 & 100.0 & 0 & 0 & 1 & 0.0 \\
\hline 7) & GDA and SA from CTR origin & 0 & 00.0 & 1 & 100.0 & 1 & 0.0 \\
\hline 8) & SA from aortic origin & 1 & 100.0 & 0 & 0 & 1 & 0.0 \\
\hline 9) & Accessory left HA from LGA & 1 & 100.0 & 0 & 0 & 1 & 0.0 \\
\hline 10) & GDA and SA from aortic origin & 0 & 00.0 & 1 & 100.0 & 1 & 0.0 \\
\hline 11) & 4A segment arterial branch from $\mathrm{CHA}$ origin & 0 & 00.0 & 1 & 100.0 & 1 & 0.0 \\
\hline 12) & $\begin{array}{l}\text { 4A segment arterial branch from proper hepatic artery origin and left HA from } \\
\text { LGA origin }\end{array}$ & 1 & 100.0 & 0 & 0 & 1 & 0.0 \\
\hline
\end{tabular}

HA: Hepatic artery, LGA: Left gastric artery, GDA: Gastroduodenal artery, SA: Splenic artery, SMA: superior mesenteric artery, CTR: Coeliac trunk. * Refers to the frequency in the study group. 


\begin{tabular}{|c|c|c|c|c|c|}
\hline Year & Author & Study population (n) & Male (n) & Female (n) & Race \\
\hline 1917 & Eaton* [24] & 206 & $138 / 200$ & $62 / 200$ & $\begin{array}{l}79 \text { White }(79 / 200) \text {, } \\
\text { Colored }(121 / 200)\end{array}$ \\
\hline 1917 & Lipshutz [25] & 83 & 73 & 10 & $\begin{array}{c}\text { Caucasian }(75 / 83) \text { and } \\
\text { negro }(8 / 83)\end{array}$ \\
\hline 1988 & Nelson et al. [10] & 50 & 24 & 26 & - \\
\hline 2003 & Saeed et al. [26] & 52 & 35 & 17 & Caucasian \\
\hline 2004 & Matsuki et al. [27] & 36 & 27 & 9 & Japanese \\
\hline 2007 & Ferrari et al. [28] & 60 & 31 & 29 & Caucasian $\dagger$ \\
\hline 2007 & Petrella et al. [7] & 89 & 72 & 17 & - \\
\hline 2009 & Chen et al. [29] & 974 & 290 & 234 & Japanese * \\
\hline 2010 & Chitra [30] & 50 & 40 & 10 & Indian $\dagger$ \\
\hline 2010 & Song et al. [9] & 5002 & 4015 & 987 & Korean $†$ \\
\hline 2011 & Natsume et al. [31] & 175 & 54 & 121 & Japanese $\dagger$ \\
\hline 2012 & Prakash et al. [32] & 50 & 34 & 16 & Indian \\
\hline 2012 & Venieratos et al. [33] & 77 & 38 & 35 & Caucasian-Greek \\
\hline 2021 & Current study & 2529 & 1703 & 826 & $\begin{array}{c}\text { Turkish (Balkan region) } \\
*\end{array}$ \\
\hline
\end{tabular}

* There were not differences between male and females.

† Not explicitly by the author but inferred in the article

most common variation was the right hepatic artery originating directly from SMA with a rate of $9.6 \%$ [16]. In our study, the frequency of variation was $25.6 \%$ and the most common variation was the right hepatic artery originating from SMA (13.44\%). Although there was no statistically significant difference in terms of variation according to gender, variation was observed more frequently in males $(68 \%)$. This variation was found to be $15 \%$ in the study by Winston et al [18] and 9.2\% in the study by De Cecco et al [19].

The second most common variation in our study is that the left hepatic artery originates from the left gastric artery with a rate of $4.74 \%$. Farganiet al found this variation as the second most common variation $(6.9 \%)$ in their study. This variation was found to be $5.2 \%$ in the study by De Cecco et al [19], and $8 \%$ in the study by Michel and Winston et al $[17,18]$. The importance of this variation is that it should be detected and ligated prior to left hepatoctomy [20].

The rate of originating the CHA from the SMA (Figure 6) has been shown in the literature at a rate of $2.5 \%$ [21], in our study this variation was found to be $1.82 \%$.

While coeliacomesenteric trunk (CMT) variation was detected as $1.15 \%$ in the current study, it was reported as $2 \%$ in the literature [22] (Figure 7).

In a retrospective evaluation of 5002 patients who underwent spiral CT and digital subtraction angiography by Song et al, they found celiac axis variations in $482(9.6 \%)$ patients, while in our study $650(25.7 \%)$ patients with CTR variation were selected in 2529 patient population [9].

The frequency of celiac truncus variations according to gender and race is summarized in Table 3 in the light of literature data.

\section{Conclusion}

Thanks to the improvements and advances in imaging techniques such as MDCT angiography and three-dimensional multiplanar techniques, knowing the rates of these vascular variations in the population, contributes to surgical procedures such as interventional radiological procedures, liver and kidney transplantation and prevents more serious complications. To the best of our knowledge, the current study includes the largest variation series in Tekirdag (Balkan region) as well as across the country. According to the present data, patients detected with arterial variation should be carefully investigated in terms of possible co-variation, the prevalence of which is $11 \%$ in this region.

Disclosures: There is no conflict of interest for all authors.

\section{Acknowledgements: None.}

Funding: None.

\section{References}

1. Standring S, Gray H. Gray's anatomy: the anatomical basis of clinical practice. 41st ed. Elsevier ltd. 2016; 1039-1088.

2. Malik S, Bordei P, Rusali A, Iliescu DM. The descending thoracic aorta morphological characteristics. ARS Medica Tomitana. 2016;22(3):186-191. DOI: https://doi.org/10.1515/arsm-2016-0031

3. Walker TG. Mesenteric vasculature and collateral pathways. Semin Intervent Radiol. 2009;26(3):167-174. doi: 10.1055/s-00291225663.

4. Sahni D, Aggarwal A, Gupta T, Kaur H, Gupta R, Chawla K, et al. Abdominal Aorta. In Tubbs RS, Shoja MM, Loukas M (Eds.), Bergman's Comprehensive Encyclopedia of Human Anatomic Variation. Hoboken, NJ, USA: John Wiley \& Sons, Inc. 2016 ; 619-681. https://doi.org/10.1002/9781118430309.ch54

5. Sehgal G, Srivastava AK, Sharma PK, Kumar N, Singh R, Parihar A, et al. Morphometry of the celiac trunk: a multidetector computed tomographic angiographic study. J Anat Soc India. 2013;62(1):23-27. Doi: https://doi.org/10.1016/S0003-2778(13)80007-X

6. Michels NA. Newer anatomy of the liver and its variant blood supply and collateral circulation. Am J Surg. 1966;112(3):337-347. Doi: 10.1016/0002-9610(66)90201-7. 
7. Petrella S, Rodriguez CFDS, Sgrott EA, Fernandes GJM, Marques SR, Prates JC. Anatomy and Variations of the Celiac Trunk. Int J Morphol. 2007;25(2): 249-257. Doi: http://dx.doi.org/10.4067/S0717-95022007000200002.

8. Saeed M, Rufai AA. Duplication of hepatic artery. Saudi J Gastroenterol. 2001;7(3):103-108.

9. Song SY, Chung JW, Yin YH, Jae HJ, Kim HC, Jeon UB, et al. Celiac axis and common hepatic artery variations in 5002 patients: systematic analysis with spiral CT and DSA. Radiology. 2010;255(1):278-288. Doi: 10.1148/radiol.09090389.

10. Nelson TM, Pollak R, Jonasson O, Abcarian H. Anatomic variants of the celiac, superior mesenteric, and inferior mesenteric arteries and their clinical relevance. Clin Anat. 1988;1(2):75-91. Doi: https://doi.org/10.1002/ca.980010202.

11. Prasoon P, Katada T, Miura K, Hirose Y, Sakata J, Wakai T. Cystic Artery Variations and Associated Vascular Complications in Laparoscopic Cholecystectomy. In Digestive System-Recent Advances: IntechOpen. 2018. DOI: 10.5772/intechopen.81200.

12. Santos PVD, Barbosa ABM, Targino VA, Silva NA, Silva YCM, Barbosa F, et al. Anatomical variations of the celiac trunk: A systematic review. Arq Bras Cir Dig. 2018; 31:e1403. Doi: 10.1590/0102-672020180001e1403.

13. Gielecki J, Zurada A, Sonpal N, Jabłońska B. The clinical relevance of coeliac trunk variations. Folia Morphol (Warsz). 2005; 64(3):123-129.

14. Iezzi R, Cotroneo AR, Giancristofaro D, Santoro M, Storto ML. Multidetector-row CT angiographic imaging of the celiac trunk: anatomy and normal variants. Surg Radiol Anat. 2008;30(4):303-310. doi: 10.1007/s00276-008-0324-7.

15. Sahani D, Mehta A, Blake M, Prasad S, Harris G, Saini S. Preoperative hepatic vascular evaluation with CT and MR angiography: implications for surgery. Radiographics. 2004;24(5):1367-1380. Doi: 10.1148/rg.245035224.

16. Farghadani M, Momeni M, Hekmatnia A, Momeni F, Baradaran Mahdavi MM. Anatomical variation of celiac axis, superior mesenteric artery, and hepatic artery: Evaluation with multidetector computed tomography angiography. J Res Med Sci. 2016;21:129. Doi: 10.4103/1735-1995.196611.

17. Michel NA. Blood supply and anatomy of the upper abdominal organs, with a descriptive atlas. Observatons on the blood supply of the liver and gallbladder (200 dissections). Philadelphia, Pa: Lippincott. 1955; 64-69.

18. Winston CB, Lee NA, Jarnagin WR, Teitcher J, DeMatteo RP, Fong Y, et al. CT angiography for delineation of celiac and superior mesenteric artery variants in patients undergoing hepatobiliary and pancreatic surgery. AJR Am J Roentgenol. 2007;189(1):W13-19. Doi: 10.2214/AJR.04.1374.

19. De Cecco CN, Ferrari R, Rengo M, Paolantonio P, Vecchietti F, Laghi A. Anatomic variations of the hepatic arteries in 250 patients studied with 64-row CT angiography. Eur Radiol. 2009;19(11):2765-2770. Doi: 10.1007/s00330-009-1458-7.

20. Kapoor V, Brancatelli G, Federle MP, Katyal S, Marsh JW, Geller DA. Multidetector CT arteriography with volumetric three-dimensional rendering to evaluate patients with metastatic colorectal disease for placement of a floxuridine infusion pump. AJR Am J Roentgenol. 2003;181(2):455-463. Doi: 10.2214/ajr.181.2.1810455.

21. Winter TC 3rd, Nghiem HV, Freeny PC, Hommeyer SC, Mack LA. Hepatic arterial anatomy: demonstration of normal supply and vascular variants with three-dimensional CT angiography. Radiographics. 1995;15(4):771-780. Doi:10.1148/radiographics.15.4.7569128.

22. Petscavage JM, Maldjian P. Celiomesenteric trunk: two variants of a rare anomaly. Australas Radiol. 2007;51 Suppl:B306-309. Doi: 10.1111/j.1440-1673.2007.01824.x.

23. Panagouli E, Venieratos D, Lolis E, Skandalakis P. Variations in the anatomy of the celiac trunk: A systematic review and clinical implications. Ann Anat. 2013;195(6):501-511. doi: 10.1016/j.aanat.2013.06.003.

24. Eaton PB. The celiac axis. Anat Rec. 1917;13(6): 369-374. https://doi.org/10.1002/ar.1090130605

25. Lipshutz B. A composivy study of the celiac axis artery. Ann Surg. 1917; 65(2):159-1 69. doi: 10.1097/00000658-191702000-00006.

26. Saeed M, Murshid KR, Rufai AA, Elsayed SE, Sadiq MS. Coexistenceof multiple anomalies in the celiac-mesenteric arterial system. Clin Anat. 2003;16(1): 30-36. https://doi.org/10.1002/ca.10093.

27. Matsuki M, Kani H, Tatsugami F, Yoshikawa S, Narabayashi I, Lee SW, et al. Preoperative assessment of vascularanatomy around the stomach by 3D imaging using MDCT before laparoscopy-assisted gastrectomy. Am J Roentgenol. 2004;183(1): 145-151. Doi: 10.2214/ajr.183.1.1830145.

28. Ferrari R, De Cecco CN, Iafrate F, Paolantonio P, Rengo M, Laghi A. Anatomical variations of the coeliac trunk and the mesenteric arteries evaluated with 64-row CT angiography. Radiol Med. 2007;112(7):988-998. English, Italian. doi: 10.1007/s11547-007-0200-2.

29. Chen H, Yano R, Emura S, Shoumura S. Anatomic variation of the celiac trunk with special reference to hepatic artery patterns. Ann Anat. 2009;191(4):399-407. doi: 10.1016/j.aanat.2009.05.002.

30. Chitra R. Clinically relevant variations of the coeliac trunk. Singapore Med J. 2010;51(3):216-219.

31. Natsume T, Shuto K, Yanagawa N, Akai T, Kawahira H, Hayashi H, et al. The classification of anatomic variations in the perigastric vessels by dual-phase CT to reduce intraoperative bleeding during laparoscopic gastrectomy. Surg Endosc. 2011;25(5):1420-1424. doi: 10.1007/s00464-010-1407-1.

32. Prakash, Rajini T, Mokhasi V, Geethanjali BS, Sivacharan PV, Shashirekha M. Coeliac trunk and its branches: anatomical variations and clinical implications. Singapore Med J. 2012;53(5):329-31.

33. Venieratos D, Panagouli E, Lolis E, Tsaraklis A, Skandalakis P. A morphometric study of the celiac trunk and review of the literature. Clin Anat. 2013;26(6):741-750. doi: 10.1002/ca.22136. 